\title{
Effectiveness of Schema-Based Instruction for Improving Seventh-Grade Students' Proportional Reasoning: A Randomized Experiment
}

\section{Citation}

Jitendra, Asha K., Jon R. Star, Danielle N. Dupuis, \& Michael C. Rodriguez. 2012. Effectiveness of Schema-Based Instruction for Improving Seventh-Grade Students' Proportional Reasoning: A Randomized Experiment. Journal for Research on Educational Effectiveness.

\section{Permanent link}

http://nrs.harvard.edu/urn-3:HUL.InstRepos:9544241

\section{Terms of Use}

This article was downloaded from Harvard University's DASH repository, and is made available under the terms and conditions applicable to Open Access Policy Articles, as set forth at http:// nrs.harvard.edu/urn-3:HUL.InstRepos:dash.current.terms-of-use\#OAP

\section{Share Your Story}

The Harvard community has made this article openly available. Please share how this access benefits you. Submit a story. 


\section{Effectiveness of Schema-Based Instruction for \\ Improving Seventh-Grade Students’ Proportional Reasoning: \\ A Randomized Experiment}

Asha K. Jitendra, University of Minnesota, 245 Education Sciences Building, 56 E. River Road, e-mail: jiten001@umn.edu, Phone: 612-626-7116, Fax: 612-624-8241

Jon R. Star, Harvard University’ Gutman Library 442, 6 Appian Way, Cambridge, MA 02138, email: jon_Star@Harvard.edu, Phone: 617-496-2511, Fax: 617-496-3095

Danielle N. Dupuis, University of Minnesota, 275G Education Sciences Building, 56 E. River Road, e-mail: dupui004@umn.edu, Phone: 612-625-0130, Fax: 612-624-8241

Michael C. Rodriguez, University of Minnesota, 170 Education Sciences Building, 56 E. River Road, e-mail: mcrdz@umn.edu, Phone: 612-624-4323, Fax: 612-624-8241

Address correspondences to: Asha K. Jitendra, Department of Educational Psychology, University of Minnesota, 245 Education Sciences Building, 56 E. River Road, Minnepolis, MN 554555. Phone: (612) 626-7116; Fax: (612) 624-8241; E-mail: jiten001@umn.edu. 


\begin{abstract}
This study examined the effect of schema-based instruction (SBI) on seventh-grade students' mathematical problem solving performance. SBI is an instructional intervention that emphasizes the role of mathematical structure in word problems and also provides students with a heuristic to self-monitor and aid problem solving. Using a pretest-intervention-posttest-retention test design, the study compared the learning outcomes for 1,163 students in 42 classrooms who were randomly assigned to treatment (SBI) or control condition. After 6 weeks of instruction, results of multilevel modeling indicated significant differences favoring the SBI condition in proportion problem solving involving ratios/rates and percents on an immediate posttest $(g=1.24)$ and on a six-week retention test $(g=1.27)$. No significant difference between conditions was found for a test of transfer. These results demonstrate that SBI was more effective than students' regular mathematics instruction.
\end{abstract}

KEYWORDS: word problem solving, ratio, proportion, and percent, middle school students, schema-based instruction 


\section{Effectiveness of Schema-Based Instruction for Improving Seventh-Grade Students' Proportional Reasoning: A Randomized Experiment}

Reform efforts in U.S. mathematic education are motivated by the need to raise the mathematics performance of students. Although the mathematical achievement of U.S. students in relation to national standards and international comparisons has shown signs of improvement over the years, there is concern that a large proportion of U.S. middle- and higher-grade students are not performing at adequate levels (National Mathematics Advisory Panel, [NMAP], 2008). On the 2009 National Assessment of Education Progress mathematics, for example, only 32\% and 12\% of Grade 8 and Grade 12 students, respectively, performed at or above the "proficient” level in mathematics (National Center for Education Statistics, 2009). These findings have translated into the need for more remedial mathematics education courses for incoming students at U.S. colleges (NMAP, 2008).

One explanation for this lackluster performance is students' difficulties with proportional reasoning (Fujimura, 2001; Lobato, Ellis, Charles, \& Zbiek, 2010). Mathematics researchers agree that proportional thinking (reasoning with ratios, rates, and percentages) is critical to understanding advanced mathematics; it provides the bridge between the numerical, concrete mathematics of arithmetic and symbolic algebra (e.g., Fuson \& Abrahamson, 2005; Lamon, 2007; Lesh, Post, \& Behr, 1988). The centrality of proportional reasoning is emphasized in the Common Core State Mathematics Standards (2010), where “developing understanding of and applying proportional relationships" in Grade 7 is one of four critical areas of focused instructional time. Furthermore, proportionality is closely associated with real-world applications and for understanding many problems in science, and technology (Karplus, Pulos, \& Stage, 1983; Lo \& Watanabe, 1997; Tourniare \& Pulos, 1985). Thus, it is disconcerting that many 
upper elementary and middle school students evidence difficulty in solving even simple proportion problems (Adjiage \& Pluvinage, 2007).

Conventional efforts to improve the teaching and learning of proportions have had limited success, as evidenced by reports showing that college students and young adults continue to struggle with proportional reasoning (Ahl, Moore, \& Dixon, 1992; Cai \& Wang, 2006; Fujimura, 2001; Jitendra, Woodward, \& Star, 2011; Lamon, 2007). Some scholars have proposed that students' difficulties with proportions may be related to the ways that this topic is treated in many mathematics texts (e.g., Lamon, 1999). Considerable research in mathematics education has focused on how to improve students' proportional reasoning (e.g., Behr, Harel, Post, \& Lesh, 1992; Lamon, 2007; Lesh, Post, \& Behr, 1988; Litwiller \& Bright, 2002), with recommendations that include providing ratio and proportion tasks in a wide range of contexts (e.g., measurements, prices, rates) and ensuring that students have experienced conceptual instruction before presenting symbolic strategies for solving proportional problems.

Accordingly, the purpose of the present randomized controlled study was to rigorously evaluate the effectiveness of one instructional intervention, schema-based instruction (SBI), which has shown promise in prior work in enhancing students' ability to solve problems with embedded ratio, proportion, and percent concepts (e.g., Jitendra, Star, Starosta, Leh, Sood, \& Caskie, 2009; Jitendra, Star, Rodriguez, Lindell, \& Someki, 2011).

\section{Theoretical Framework and Review of Research}

Our SBI is a multicomponent intervention that is grounded in the research on expertise and schema theory. Four major features underlie the SBI framework - priming the mathematical structure of problems, visual representations, explicit teaching of problem solving heuristics, and procedural flexibility. 


\section{Theoretical Framework}

Priming the mathematical structure of problems. From both the expertise literature and schema theory, it is clear that cognizance of the role of the mathematical (semantic) structure of a problem is critical to successful problem solving (Sweller, Chandler, Tierney, \& Cooper, 1990). A defining characteristic of expert problem solvers is distinguishing "relevant information (related to mathematical structure) from irrelevant information (contextual details), perceiving rapidly and accurately the mathematical structure of problems and in generalizing across a wider range of mathematically similar problems” (Van Dooren, de Bock, Vleugels, \& Verschaffel, 2010, p. 22). As such, experts often solve problems using pattern recognition procedures and working forward from problem classification to solution (Lajoie, 2003; Yekovich, Thompson, \& Walker, 1991). There is evidence that training that focuses on priming the problem structure leads to improved schema development (Chen, 1999; Quilici \& Mayer, 1996, 2002). Schemata are hierarchically organized, cognitive structures that are acquired and stored in long-term memory that "allow us to treat multiple elements of information in terms of larger higher-level units (or chunks)” (Kalyuga, 2006, p. 2). Organizing problems on the basis of structural features (e.g., ratio/rate problem) rather than surface features (i.e., the problem context or cover storybicycle problem) can evoke the appropriate solution strategy.

In the domain of arithmetic word problems in the elementary grades, research has identified basic types of problem situations or schemata (e.g., Change, Group, Compare) that highlight the mathematical structure of these problems (see Carpenter, Fennema, Franke, Levi, \& Empson, 1999). There is strong empirical support for the benefits of explicit schema training in solving arithmetic word problems (e.g., Fuchs, Powell, et al., 2009; Fuchs, Seethaler, et al., 2008; Fuchs, Zumeta, et al., 2010; Fuson \& Willis, 1989; Jitendra, Griffin, Haria, Leh, Adams, \& 
Kaduvetoor, 2007). In contrast, even though considerable research on proportion problem solving has been conducted (e.g., Behr, Harel, Post, \& Lesh, 1992; Fuson \& Abrahamson, 2005; Lamon, 2007; Lesh, Post, \& Behr, 1988; Litwiller \& Bright, 2002), there is not a wellestablished typology of basic problem types of proportion problems that emphasizes mathematical structure. Rather, existing typologies focus only on the mathematical subtopic with the broad range of proportion problems (e.g., rate, ratio, scale drawings, percent, percent of change) (see Greer, 1992; Marshall, 1995; Vergnaud, 1983). However, emerging work in this domain has provided strong evidence that the establishment of a typology for proportion word problems, along with instruction that emphasizes underlying mathematical structure, can be effective in the middle grades with proportional reasoning (e.g., Jitendra et al., 2009; Jitendra et al., 2011; Xin, Jitendra, \& Deatline-Buchman, 2005).

Visual representations as mathematical tools. In addition to recognition of problem structure, visual representations are equally important in facilitating solution to a problem (Stylianou, 2011). According to Yekovich, Thompson, and Walker (1991), "experts and novices also differ in the way they mentally represent problems; novices seem to represent superficial aspects of problems whereas experts represent the 'semantics' of problems" (p. 190). Solving word problems requires mentally representing the different elements described in the problem text. Some students have difficulty generating a representation of the problem or holding the representation in working memory to act upon it. As such, visual representations (e.g., tables, graphs, diagrams) that effectively link the relationships between quantities in the problem with the mathematical operations needed to solve or represent the problem are helpful tools in promoting problem solving (Sellke, Behr, \& Voelker, 1991). The use of schematic representations in this manner is an integral component of SBI in many prior studies (e.g., Fuchs, 
Seethaler, et al., 2008; Fuson \& Willis, 1989; Jitendra et al., 2009; Jitendra et al., 2007; Jitendra et al., 2011; Xin, 2008; Xin et al., 2005). In contrast to pictorial representations of problems that include concrete but irrelevant details that "are superfluous to solution of the math problem" (Edens \& Potter, 2006, p. 186), schematic representations that allow students to look beyond surface features of word problems to interpret and elaborate on information, which may be especially important for ratio and proportion problems (Hegarty \& Kozhevnikov, 1999; Marshall, 1995; Pape \& Tchoshanov, 2001).

Explicit instruction on problem-solving heuristics. Teaching heuristics - systematic approaches to represent, analyze, and solve problems - as a means to enhance student learning has received considerable attention in mathematics education. On the one hand, universal heuristics such as Pólya’s (1990/1945) four-step problem solving model (i.e., understand the problem, devise a plan, carry out the plan, and look back and reflect) have come under scrutiny for several reasons, including the failure to reliably lead to improvements in students' word problem solving performance (Lesh \& Zawojewski, 2007). Schoenfeld (1992) argued that the strategies listed in Polya’s heuristic are descriptive and do not provide the necessary detail for individuals who are not already familiar with the strategies to effectively use them. On the other hand, teaching a number of domain-specific, prescriptive procedures has its own limitations, most notably the failure to affect transfer (Schoenfeld, 1992). Although studies have resulted in moderate mean effect sizes, the effectiveness of heuristic training seems to be related to classroom-related conditions such as how heuristics are taught or integrated into the mathematics curriculum (Goldin, 1992; Hembree, 1992; Koichu, Berman, \& Moore, 2007). Building on the work of Marshall (1995) and Mayer (1999), we addressed some of these limitations. The heuristic in SBI comprises four separate but interrelated problem solving procedural steps: 
problem schema identification (schema knowledge), representation (elaboration knowledge), planning (strategic knowledge), and solution (execution knowledge) (Marshall, 1995). Several studies (Jitendra, Griffin, McGoey, Gardill, Bhat, \& Riley, 1998; Jitendra et al., 2007; Xin et al., 2005) have shown that heuristic training in SBI linked to particular problem types (e.g., additive and multiplicative compare, proportion) is more effective than heuristic training involving a version of Polya's problem solving model for improving student learning and impacting transfer to solve novel problems.

Procedural flexibility. In addition to the ability to attend to the mathematical structure of problems and represent the problem using schematic diagrams, expert problem solvers have deep and robust knowledge of problem solving procedures, including when, how, and why to use a broad range of methods for a given class of problems is important (Hatano, 2003; Star, 2005, 2007). According to Star (2005), deep procedural knowledge can be characterized as "knowledge of procedures that is associated with comprehension, flexibility, and critical judgment” (p. 148). Of particular interest here is flexibility, which is knowledge of multiple solution methods for solving certain types of problems and the ability to choose the most appropriate method for a particular problem (Star, 2005). An emphasis on having students actively compare, reflect on, and discuss multiple solution methods is a central feature of mathematics reform efforts (Silver, Ghousseini, Gosen, Charalambou, \& Strawhun, 2005). Further, recent studies by Rittle-Johnson and colleagues (e.g., Rittle-Johnson \& Star, 2007) provide empirical evidence for improving student learning when instruction emphasizes and supports comparing and contrasting multiple solution methods. 


\section{Research Related to SBI Intervention}

We found only three randomized controlled studies with middle school students that directly link SBI to measured student outcomes in solving proportion word problems involving ratios/rates and percents (Jitendra et al., 2009; Jitendra et al., 2011; Xin et al., 2005). First, Xin et al. conducted a small study with 22 middle school students with learning problems in grades 6 through 8. Students who received about three to four 60-min researcher-taught tutoring sessions per week for a total of 12 sessions in solving a limited set of mathematical topics related to proportion (ratio and proportion word problems) scored higher than students who were instructed in a general problem solving heuristic. The effect sizes comparing the SBI group with the control group were large following treatment $(d=1.69)$ and on the retention tests $(d>2.50)$. Further, transfer $(d=0.89$ ) occurred to novel problems derived from standardized mathematics achievement tests.

The more recent work of Jitendra and colleagues (e.g., Jitendra et al., 2009) also tested the potential benefits of SBI for 148 students from eight $7^{\text {th }}$ grade mathematics classrooms, with classrooms randomly assigned to SBI or "business as usual" control condition that received the same amount of instruction on the same topics. In contrast to the work by Xin et al. (2005), this study expanded the topics included within the intervention (including ratios, equivalent fractions, rates, proportion, scale drawings). In addition, the study extended the Xin et al. study by increasing the number and diversity (low-, average-, and high-achieving) of students involved, having classroom teachers provide all instruction, emphasizing multiple solution strategies, and administering a 4-month retention test. Compared to students in the control group, students in the SBI group improved their word problem solving performance with moderate effects at immediate posttest $(d=0.45)$ and on the retention test $(d=0.56)$. 
Jitendra et al. (2011) built on the two studies described above to evaluate the effectiveness of SBI on seventh grade students' learning to solve proportion problems in a randomized controlled trial. This study addressed several limitations in research design of the Jitendra et al. (2009) study such as significantly extending the class time allotted to the intervention; providing longer professional development to classroom teachers; exploring the robustness of SBI by conducting the study in two districts that used very different mathematics programs; and extending the focus of proportion problem solving to percents, including simple interest. At the end of treatment, students receiving SBI intervention outperformed students in the control condition on the problem-solving immediate posttest (Hedges' $g=0.75$ ). However, the improved problem solving skills were not maintained a month after the end of the intervention. Yet the effects on this delayed posttest were practically significant ( $g=0.46$ ), suggesting a lack of power given the small sample size $(n=21$ classrooms) to detect significant differences.

The present study extended the work of Jitendra et al. (2011) by increasing the number of students involved and by reducing the direct involvement from the research team in supporting SBI classroom implementation. Although research team members continued to provide support to teachers as needed, the support was minimal, focusing on logistical issues rather than the level of curriculum implementation intensity provided in previous studies. We posed the following three research questions to guide the SBI research study: What is the effect of the SBI intervention on seventh graders' (1) problem solving performance, (2) retention of problem solving skills over 6 weeks, and (3) transfer of problem solving skills? 


\section{Method}

\section{Sample}

A subset of seventh-grade teachers at three suburban public schools in Minnesota participated in the study. The three districts included in our sample used MathThematics (Billstein \& Williamson, 2008), Math Course (Larson et al., 2007), and Math Connects Course (Day, Frey, \& Howard,, 2009) at the middle school level. The districts varied somewhat on student enrollment (10,113, 20,510, and 16,488 students, respectively) and on student characteristics; students were mostly Caucasian (61\%, 54\%, and 77\%), with 36\%, 36\%, and 16\% receiving free or reduced lunch.

Our sample consisted of 1,163 seventh-grade students and their 15 teachers from 42 classrooms at six middle schools in the three school districts. The mean age of the students was $12.83(S D=0.38)$. The majority of the students were Caucasian $(60 \%)$, with $17 \%$ African American, 11\% Asian, 10\% Hispanic, and 1\% American Indian. Approximately 34\% of students received free or reduced lunch, $11 \%$ were special education students, and 7\% were English language learners (see Table 1 for student demographic information by condition). Students were initially assigned to one of two conditions: control or SBI.

The teachers of these students (11 females and 4 males) had a mean age of 31.27 years (range: 24 to 53 years). They ranged in mathematics teaching experience from 1 to 11 years $(M=$ 6.2 years). Fourteen of the 15 teachers were Caucasians; one teacher was African-American. Six teachers had an undergraduate degree in mathematics, whereas nine teachers had master's degrees. Fourteen of the teachers held secondary education certification. 


\section{Design and Procedure}

We used a randomized treatment-control, pretest-posttest design. Blocking by teacher at each school, the 42 classrooms were randomly assigned to the SBI ( $n=594$ students) or control ( $n=569$ students) condition so that classrooms were nested in instructional treatments, and students were nested in classrooms and treatments. Blocking by teacher meant that teachers with multiple classrooms taught both treatment and control classrooms, while teachers with a single classroom were randomly assigned to teach either a treatment or control classroom. We chose to block the assignment of conditions by teacher to reduce the variability between the conditions, and as such increase precision. Blocking is typically done to reduce a source of variability that is not of substantive interest - in this case, variability due to teachers. By blocking on teacher we control for the effects of teachers, which gives us a more precise estimate of the treatment effect. Professional development for all teachers (described below) was provided prior to the start of the intervention. In treatment classrooms, SBI was implemented in five 45-50 min mathematics classes a week over 6 weeks. In the same time period (6 weeks), students in the control condition were taught the same topics as in SBI classrooms but using instructional practices specified in their textbook; that is, with no special emphasis on the underlying mathematical structure of the problems.

We collected pretest data on mathematical problem solving and problem-solving transfer two weeks before the intervention started. Posttest data on the same variables were collected at the end of the intervention as well as six weeks later on the problem-solving test to measure retention of problem solving skills. All measures were group-administered to students by their classroom teachers. We gathered implementation data via classroom observations. Below is a 
description of the professional development, the intervention, the assessment of treatment implementation, and the measures.

\section{Professional Development}

All teachers in this project participated in 12 hours of professional development. The content and focus of the SBI training focused on the topics of ratio, proportion, and percent, particularly as they related to students' understanding, implementation of SBI and importance of adhering to the standard "as-usual" curriculum in the control classrooms. The training consisted of: (a) engaging teachers in a discussion of how their students would approach ratio and proportion types as well as analyzing expected student solutions, explanations, and difficulties; (b) emphasizing the underlying structure of ratio and proportion problem types and using schematic diagrams to represent the problem, (c) presenting multiple short video segments to illustrate the SBI intervention implemented by a teacher from the previous year and discussing how to introduce the procedures inherent to the SBI approach and elicit student discussions, and (d) having teachers read the lesson plans and discuss implementation of SBI.

\section{Intervention}

SBI. The instructional content consisted of ratio, proportion and percent topics. Within SBI and as described below, teachers used four instructional practices. First, teachers primed the mathematical structure of problems by focusing on a variety of problem types related to proportions (see Table 2 for classification of these problems into schemata in the SBI curriculum). Teachers were encouraged to stimulate students' thinking about how problems within and across types are similar and different. Second, teachers visually mapped information in the problem using schematic diagrams. For example, to visually represent information in a proportion problem, teachers prompted students to identify the ratios in the problem and write 
them in the proportion diagram (see Table 2). Third, teachers provided explicit instruction on a problem-solving heuristic (DISC: D - Discover the problem type, I - Identify information in the problem to represent in a diagram, $\mathrm{S}$ - Solve the problem, $\mathrm{C}$ - Check the solution), with accompanying deep-level questions for each step in the heuristic (e.g., Why this is a proportion problem? How is this problem similar to or different from one I already solved?). Finally, teachers worked to develop students' procedural flexibility, including explicit teaching of multiple solution methods for solving proportion problems and being cognizant of specific methods that are more efficient than others. Teachers modeled by thinking aloud as they engaged in these four practices and scaffolded by gradually shifting responsibility for problem solving to the students. (For further details of the SBI instructional approach, see Jitendra et al., 2009; Jitendra et al., 2011)

Control classrooms. Information on curricula used in control classrooms was gathered by reviewing the procedures outlined for teaching ratio, proportion, and percent topics in the three district-adopted mathematics textbooks as well as three formal observations of each teacher's mathematics activities (see section below on measures). District 1 used MathThematics Book 2 (Billstein \& Williamson, 2008), which is a 'reform-oriented' curricula developed with funding from the National Science Foundation. District 2 employed Math Course 2 (Larson et al., 2007), and District 3 used Math Connects Course 3 (Day et al., 2009) - both of which are more 'traditional' mathematics curricula. Although the control classrooms used different textbooks, they covered the same topics (e.g., ratios, rates/proportions, scale drawings, fractions, decimals, and percent). Instructional procedures differed from SBI in that core practices did not explicitly (a) emphasize the underlying mathematical structure of the problems, (b) promote problem solving heuristics, or (c) teach multiple solution strategies - cross multiplication was the 
most common approach used across all three textbooks. Instructionally, the most salient differences between the control curricula were that the texts used in District 2 and 3 relied more heavily on whole class direct instruction, while the text used in District 1 made extensive use of explorations of mathematical ideas in small groups. Anecdotal evidence suggests that these three curricula are used widely, both in the state of Minnesota and across the US more generally.

\section{Classroom Observations of Fidelity}

We videotaped 39 observations of classroom instruction in the treatment condition and 42 observations in the control condition during the 6-week intervention to ensure fidelity of treatment and to identify contamination of instruction, if any, in the control classrooms. This sampling resulted in three observations per teacher within condition. Below we describe the fidelity measures and the procedures used to establish treatment fidelity. as well as our assessment of evidence of contamination of instruction.

Fidelity measures. Two observation instruments were used to describe and measure teachers' adherence to the implemented intervention or curriculum (SBI or control). The fidelity measure for the treatment condition consisted of 5 items measuring general teacher behaviors (e.g., provides positive feedback) and 15 items corresponding to critical elements of the treatment (e.g., solving the problem using the DISC 4-step strategy). Examples of items associated with Step 1 of the DISC strategy are identifying the problem type by focusing on the key problem features and discussing whether the problem is similar to/different from previously solved problems. The observation instrument for the control condition consisted of the same 5 items measuring general teacher behaviors and 4 items specific to the SBI curriculum to determine if control teachers spontaneously provided instruction that was similar to the key components of SBI and to examine evidence of cross contamination. 
Fidelity. Fidelity was measured using a dichotomous rating scale for each item on the observation forms. Interrater agreement computed via a second rater observing the videotape and rating one randomly selected videotape of a teacher per condition averaged .99 for SBI and .98 for the control condition. The results for key fidelity variables are presented in Table 3. Items in Section I represent teacher behaviors that we expected to observe in both treatment and control classrooms (e.g., sets purpose, provides positive feedback). Results indicate that on average, SBI teachers $(M=.97 ; S D=.17)$ engaged in these behaviors slightly more often than control teachers $(M=.91 ; S D=.29)$, the largest difference was on the item "provides lesson closure" (see Table 3). Section II includes items related to teacher's SBI implementation of the DISC four-step procedure. While we only expected to see these behaviors performed by SBI teachers, we included these items on our control fidelity measure. As seen in Table 3, SBI teachers averaged .79 to .93 across these four items. For the most part, control teachers were not observed implementing these steps with the exception of step 4 (i.e., solves the problem). Section III consists of items related to teacher or student use of the DISC checklist, which was assessed only in SBI classrooms. Results showed that teachers modeled and prompted use of the DISC checklist more often than students’ use of the checklist across the three observations.

More generally, Table 3 shows that fidelity scores for teacher behaviors were relatively stable across the three observations for both treatment and control classes. These data suggest that teachers in control classes consistently adhered to their curriculum and teachers in treatment classes consistently implemented SBI at a moderately high level over time to allow us to attribute group differences to the implementation of SBI. 


\section{Measures}

Mathematical problem-solving tests. The experimenter-designed 23-item mathematical problem-solving test (Jitendra et al., 2009; Jitendra et al., 2011) measures students’ ability to solve problems involving ratios/rates and percents using standardized protocol and scoring procedures. We used the same assessment as a pretest, posttest, and delayed posttest (6 weeks following instruction). The problem-solving test consists of multiple-choice items derived from the TIMSS, NAEP and state assessments, with two short-answer conceptual item designed to assess students' knowledge of ratio and percent of change concepts. To estimate reliability we fit the parallel, tau-equivalent, and congeneric measurement models to the pretest, posttest, and delayed posttest separately. Results indicated that the congeneric model fit the data best with all RMSEA less than 0.04 and all GFI greater than 0.95. Reliability estimates from the congeneric model were $0.69,0.79$, and 0.82 for the pretest, posttest, and delayed posttest, respectively. With the exception of the conceptual items, all items were scored for accuracy of the answer. The mean interscorer agreement assessed by two research assistants independently scoring 33\% of the protocols was $99.78 \%$ for pretest, $99.96 \%$ for posttest, and $99.96 \%$ for delayed posttest.

For the short-answer conceptual items, students had to explain their reasoning, and responses were scored on 4- and 6-point scales. To score these items, we first constructed a scoring template based on a sample $(n=90)$ of protocols randomly selected from both instructional conditions. Next, two research assistants scored a sample of the protocols using the scoring criteria to obtain consensus followed by independent, blind scoring of the protocols (interscorer agreement on $20 \%$ of explanations was $98 \%$ and $94 \%$ for the ratio and percent of change items, respectively). 
In addition, we administered an 18-item mathematical problem-solving transfer test (Jitendra et al., 2011) consisting of items derived from the TIMSS, NAEP, and state assessments that were not directly aligned with the taught content. The transfer test assessed whether SBI impacted transfer to novel problems having the same mathematical structure but of a different type or having a modified problem structure (e.g., probability) but which require an understanding of ratios. The same assessment was used as a pretest and posttest. As with the problem-solving test, we fit the parallel, tau-equivalent, and congeneric measurement models to the transfer pretest and posttest separately. Again, results indicated that the congeneric model fit the data best with all RMSEA less than 0.03 and all GFI greater than 0.96 . Reliability estimates from the congeneric model were 0.73 and 0.81 for the pretest and posttest, respectively The mean interscorer agreement for 33\% percent of the protocols assessed was $99.97 \%$ for pretest and $99.80 \%$ for posttest.

\section{Data Analysis Procedures}

To assess differences in mathematical problem solving between the treatment and control groups, we fit a series of multilevel models using HLM 6 (Raudenbush, Bryk, \& Congdon, 2004). The outcome variables included in the analyses were the mathematical problem solving posttest, delayed posttest, and transfer posttest. Pretest scores, ethnicity, eligibility for free/reduced priced lunch and special education status served as student-level and classroomlevel covariates. The treatment variable and a set of dummy variables representing the schools served as additional classroom-level covariates. Preliminary analyses indicated no significant interaction between the treatment variable and pretest scores for any of the outcome variables; as such, the interactions are excluded from all analyses that follow. Descriptive statistics for the pretest, posttest, and delayed posttest measures by treatment group for each school are presented 
in Table 4. Descriptive statistics for the transfer pretest and posttest measures by treatment group for each school are presented in Table 5.

For each outcome, the Level 1 model contained four student-level variables: pretest score, ethnicity, free or reduced priced lunch eligibility, and special education status. Ethnicity was dummy coded so that minority students (African American, Hispanic, Asian, Native American) were coded as 0 and Caucasian students were coded as 1 . Eligibility for free or reduced priced lunch was coded so that students who were eligible for free or reduced priced lunch were coded as 1 and students who were not eligible were coded as 0 . Special education students were coded as 1 and general education students were coded as 0. Similarly, each Level 2 model contained variables representing classroom and school level information. Level 2 variables included: treatment group (coded $1=$ treatment, $0=$ control); average classroom pretest score; percent non-minority students, percent of students eligible for free or reduced priced lunch and percent of special education students in a classroom; and five dummy variables representing the six schools included in the sample (School F served as the reference school). We also created variables representing treatment by school interactions (product terms), but these effects were not significant in any analyses we conducted so they are not discussed further or included in the results. All Level 1 variables were group-mean centered so that the Level 1 intercepts could be interpreted as classroom means. All Level 2 variables were grand-mean centered. Because of the small number of Level 2 units ( $J=42$ classrooms), restricted maximum likelihood estimation was used for all analyses reported (Raudenbush \& Bryk, 2002). 
Models for Mathematical Problem Solving (Posttest and Delayed Posttest) and Transfer of

\section{Mathematical Problem Solving}

For the mathematical problem-solving posttest, delayed posttest, and transfer test, we fitted three different models. The first model was an unconditional model and contained no covariates at either level. This model allowed us to assess the amount of variation in classroom means, unadjusted for the influence of covariates. The second model included all of the student demographic variables and pretest scores at Level 1 and Level 2. All of the Level 1 covariates were treated as fixed effects at Level 2, so the Level 2 variables were only predictors of Level 1 intercepts. In the third and final model the treatment variable and the five dummy variables representing schools were included as predictors of Level 1 intercepts. The same models were fitted to the posttest, delayed posttest, and transfer test. The final fitted model for mathematical problem solving and transfer tests was:

Level 1 model:

$Y_{i j}=\beta_{0 j}+\beta_{1 j}($ pretest $)+\beta_{2 j}($ ethnicity $)+\beta_{3 j}(F R L)+\beta_{4 j}(\operatorname{SpEd})+r_{i j}$

Level 2 model:

$$
\begin{aligned}
\beta_{0 j} & =\gamma_{00}+\gamma_{01}(\text { treatment })+\gamma_{02}(\text { pretest })+\gamma_{03}(\text { ethnicity })+\gamma_{04}(F R L)+\gamma_{05}(\operatorname{SpEd}) \\
& +\gamma_{06}(\text { SchoolA })+\gamma_{07}(\text { SchoolB })+\gamma_{08}(\text { SchoolC })+\gamma_{09}(\text { SchoolD })+\gamma_{010}(\text { SchoolE })+u_{0 j} \\
\beta_{1 j}= & \gamma_{10} \\
\beta_{2 j}= & \gamma_{20} \\
\beta_{3 j}= & \gamma_{30} \\
\beta_{4 j} & =\gamma_{40}
\end{aligned}
$$

We examined model assumptions for all the analyses. This included examining the normality of Level 1 residuals and the homogeneity of Level 1 variances. No major violations to either of these assumptions were found for any of the models. Likewise, Level 1 residuals were 
uncorrelated with Level 1 variables, and Level 2 random effects were uncorrelated with Level 2 variables. The Level 2 random effects showed no significant deviations from normality.

\section{Results}

Evidence of contamination. Because 12 of the 15 teachers in the present study taught both SBI and control classrooms, we performed a series of sensitivity analyses to assess the possibility of contamination between the two conditions. Our first step was to perform a series of independent samples $t$-tests, where the posttest, delayed posttest, and transfer posttest served as the dependent variables. The independent variable comprised two groups of teachers, those who taught treatment or control classrooms $(n=3)$ and those who taught treatment and control classrooms $(n=12)$. Results indicated no statistically significant differences between the two groups of teachers on any of the outcome variables (all $p>.30$ ).

Because we were concerned that teachers who taught SBI and control classrooms might be likely to use SBI materials in their control classrooms, we performed another series of independent samples t-tests. Only teachers who taught control classrooms were included in these analyses $(n=14)$ and items and total scores from our fidelity of implementation (FOI) data served as dependent variables. The independent variable consisted of two groups of teachers, those who taught only control classrooms $(n=2)$ and those who taught treatment and control classrooms $(n=12)$. Our focus in these analyses was on a set of items (Section II) that assessed the extent to which control teachers used SBI materials or the SBI approach in their control classrooms. There were no significant differences between the two groups of teachers on any of the items or the total score for this FOI section. These results suggest that teachers who taught both SBI and control classrooms were equally likely to use SBI materials in their control classrooms as teachers who had no exposure to SBI. 
Our final analysis to explore the possibility of contamination was to refit our final HLM models including teachers as a third level (only intercepts were allowed to vary). We used these analyses to assess the amount of variation in the posttest, delayed posttest, and transfer posttest that could be attributed to between teacher differences. The results indicated that teachers accounted for $2 \%$ of the variation in the posttest and delayed posttest and no variation in the transfer posttest. The values for the posttest and delayed posttest were not significant. These results indicate that teachers do not contribute to significant variation in the outcomes. Likewise, including teachers as a third level in the model did produce any significant changes to the final model coefficients or effect sizes.

Based on these analyses, we did not find evidence that contamination impacted our results. More specifically, among teachers who taught both SBI and control classrooms, our classroom observations did not indicate that SBI materials and instructional practices were widely used in control classrooms. In addition, students of teachers who taught both SBI and control classrooms did not perform better on any of our measures than students of teachers who only taught in control classrooms. However, it should be noted that all of the statistical tests described above suffer from a lack of statistical power because of the small sample sizes and should be interpreted with caution given the unbalanced groups.

\section{Mathematical Problem Solving (Posttest)}

To estimate the intraclass correlation (ICC), we fitted an unconditional model to the posttest that contained no covariates at Level 1 or Level 2. The ICC, which measures the proportion of variance in mathematical problem solving between classrooms, was .222 for the posttest, which indicates that $22.2 \%$ of the variance in the posttest was between classrooms, and $77.8 \%$ of the variance was within classrooms. The between classroom variance was statistically 
significant, $\tau_{00}=7.33, \chi^{2}(41)=330.59, p<.001$. Next, we estimated a model that contained all of the student demographic variables and the pretest variable at both Level 1 and Level 2. The addition of these covariates reduced the within classroom variability in the posttest by $37.3 \%$ and the between classroom variation by $80.8 \%$. However, there was still significant variation in classroom intercepts to be explained $\left(\tau_{00}=1.41, \chi^{2}(37)=199.97, p<.001\right)$. Our final step was to add the treatment variable and the school dummy variables as predictors of the Level 1 intercepts. The inclusion of these variables explained an additional $6.9 \%$ of the between classroom variation, indicating that the final model explained $87.7 \%$ of the variance between classrooms. However, significant variation in classroom intercepts remained unexplained $\left(\tau_{00}=\right.$ $\left.0.61, \chi^{2}(31)=61.08, p=.001\right)$. The results of the final model can be found in Table 6 .

Given the coding and centering schemes used in the analysis, the grand mean intercept, $\gamma_{00}=17.55, t(31)=101.60, p<.001$, represents the predicted posttest score for an average student (i.e., for a student at the mean on each covariate). Significant predictors of Level 1 intercepts (classroom means) included the treatment variable $\left(\gamma_{01}=1.48, t(31)=3.99, p<.001\right)$ and the pretest scores $\left(\gamma_{05}=0.93, t(31)=6.03, p<.001\right)$. Results indicate that students in the SBI condition scored on average 1.48 points higher than students in the control condition, with an effect size $(g)$ of 1.24 . We calculated an effect size for the treatment variable by dividing the condition coefficient $\left(\gamma_{01}\right)$ by the standard deviation of the classroom intercepts (i.e., the square root of $\tau_{00}$ ) from the previous (student demographic) model (Hedges, 2007).

\section{Mathematical Problem Solving (Delayed Posttest)}

The unconditional ICC for the delayed posttest was .222, indicating that $22.2 \%$ of the variance was between classrooms, $\tau_{00}=6.96, \chi^{2}(41)=324.34, p<.001$, and $77.8 \%$ was within classrooms. Our next step involved fitting a model that contained all of the student demographic 
variables and the pretest variable at both Level 1 and Level 2, which reduced the within classroom variability by $35.4 \%$ and the between classroom variation by $87.9 \%$. However, there was still significant variation in classroom intercepts to be explained $\left(\tau_{00}=0.84, \chi^{2}(37)=87.20\right.$, $p<.001$ ). Our last step involved adding the treatment variable and the school dummy variables as predictors of the Level 1 intercepts, which explained an additional $9.2 \%$ of the between classroom variation. In total, the final model explained $97.1 \%$ of the between classroom variance, with no significant variation between classrooms left to be explained $\left(\tau_{00}=0.20, \chi^{2}\right.$ $(31)=41.38, p=.10)$. Table 7 presents results of the final model.

The grand mean intercept, which represents the predicted delayed posttest score for an average student, was estimated to be $17.00, t(31)=120.70, p<.001$. Significant predictors of Level 1 intercepts included the treatment variable $\left(\gamma_{01}=1.17, t(31)=3.88, p=.001\right)$ and the pretest scores $\left(\gamma_{05}=0.83, t(31)=6.62, p<.001\right)$. The results indicate that students in the SBI condition scored on average 1.17 points higher than students in the control condition $(g=1.27)$.

\section{Transfer of Mathematical Problem Solving}

The unconditional ICC for the transfer posttest was .165, indicating that $16.5 \%$ of the variance was between classrooms and $83.5 \%$ was within classrooms. The between classroom variance was statistically significant, $\tau_{00}=1.86, \chi^{2}(41)=239.94, p<.001$. Next, we added all of the student demographic variables and the pretest variable at both Level 1 and Level 2, which reduced the within classroom variability by $39.4 \%$ and the between classroom variation by 93.6\%. However, there was still significant variation in classroom intercepts to be explained $\left(\tau_{00}\right.$ $\left.=0.12, \chi^{2}(37)=56.77, p=.02\right)$. As above, our final step was to add the treatment variable and the school dummy variables as predictors of the Level 1 intercepts. The inclusion of these variables explained no additional between-classroom variation. As such, the final amount of 
between classroom variance explained by the variables was 93.6\%. However, there was still significant variation in classroom intercepts left unexplained $\left(\tau_{00}=0.15, \chi^{2}(31)=52.38, p=\right.$ $.01)$.

The grand mean intercept was estimated to be 11.48, $t(31)=120.24, p<.001$, which represents the predicted transfer posttest score for an average student. Pretest scores $\left(\gamma_{05}=0.97\right.$, $t(31)=6.81, p<.001)$ were the only significant predictor of the transfer posttest. The results did not indicate a statistically significant effect for the treatment variable, $\gamma_{01}=0.23, S E=0.21, t(31)$ $=1.12, p=.247$.

\section{Discussion}

The main objective of our study was to investigate the effects of SBI that focused on priming the mathematical structure of problems, use of visual representations, explicit instruction in teaching heuristics, and an emphasis on multiple solution strategies on seventh graders' mathematical problem solving involving ratios, proportions, and percents compared to students in regular mathematics programs in their schools. The following three major results emerged from this study. First, students in the treatment classes outperformed students in the comparison classes on a measure of problem solving. The effect size was large $(g=1.24)$ when students in SBI classes were compared to control students and exceeded the effect sizes reported in the SBI literature for ratio, proportion, and percent problem solving when delivered by classroom teachers rather than researchers (Jitendra et al., 2009; Jitendra et al., 2011). Second, relative to control students, SBI students maintained their superior performance on the delayed (follow-up) posttest. The associated effect size was large $(g=1.27)$ and also exceeded the effect sizes in prior SBI research with middle school students (Jitendra et al., 2009; Jitendra et al., 2011). These 
findings confirm the efficacy of SBI as a feasible intervention to enhance students' problem solving performance.

Third, students in the SBI classes did not outperform the control students on the transfer test of problem solving. It is worth pointing out that we performed a priori power analyses on all of the HLM models using the Optimal Design software (Raudenbush et al., 2011). The results of these analyses indicated that we had enough statistical power $(\beta=.80)$ to detect large effects (i.e., d's $>$.60). As such, the finding for the transfer measure is discouraging. However, our result is consistent with a prior study by Jitendra et al. (2011). Similar to Jitendra et al., there are at least two reasons for the lack of transfer effect. First, even though items for both the posttest and transfer measures were derived from the TIMSS, NAEP, and state standardized mathematics assessments, the lack of SBI transfer may be attributed to differences between the posttest and transfer test with regard to the problem types sampled. For example, the posttest included ratio, proportion, and percent items that aligned with seventh-grade mathematics content standards; the transfer test comprised novel and complex items (e.g., probability) that were probably less sensitive to the effects of SBI. Second, the finding might be better clarified using Wagner's (2006) theory of transfer-in-pieces that highlights the importance of multiple examples. While we did provide many worked examples that emphasized the critical features of problem types, it may be the case that longer duration of SBI is necessary to achieve transfer. As noted in Wagner, transfer is "the incremental growth, systematization, and organization of knowledge resources that only gradually extend the span of situations in which a concept is perceived as applicable” (p. 10). At the same time, and consistent with the overall aims of SBI, transfer results may be improved by priming students to focus on the similarities and differences between new domains (e.g., probability) and previously learned concepts of ratio and proportion. Future research 
should explore the performance of students when provided with even longer interventions and instruction that makes explicit connections to content outside of the instructional domain.

Together, these results suggest that 6 weeks of regular classroom instruction in ratio, proportion, and problem solving could potentially be supplanted by SBI. In this study, SBI was more effective than the mathematics instruction used in participating schools, reflecting the usefulness of the principles incorporated in SBI (i.e., priming the mathematical structure). In addition, our results suggest that these findings generalize to the total sample: Even though general education students outperformed special education students and Caucasian students outperformed minority students, the pattern of findings favoring SBI remained the same in these subgroups. Further, we are encouraged about the potential effectiveness of SBI resulting from a relatively brief period of time and requiring only two days of professional development, especially since implementing any novel "instructional practice requires considerable change on the part of teachers” (Yoon, Duncan, Lee, Scarloss, \& Shapley, 2007, cited in Vaughn, et al., 2011, p. 958). This relatively brief amount of time for professional development is feasible for most schools.

While acknowledging the importance of interventions designed to more broadly impact students' proportional thought processes, this study indicates the relevance of a somewhat more targeted focus of SBI. In light of the literature on expert/novice differences in problem solving, SBI in this study targeted an appropriate set of mathematical competencies (e.g., problem comprehension in terms of recognizing the underlying mathematical structure, procedural flexibility) that are integral to successful word problem solving. The present findings point to the merits of strategy instruction using an explicit problem solving heuristic that emphasizes the underlying problem structure via visual representations and encourages procedural flexibility. 


\section{Limitations}

We need to consider at least two limitations of this study. Based on the design of this study, the contamination from treatment to control classes is a possibility since the majority of teachers taught in both conditions. However, as noted above, we monitored control classrooms during the observations for contamination, which was none to minimal. Second, because SBI is a multicomponent intervention, we cannot determine which of the components might be associated with impact and which may be less influential to mathematical problem solving. As with all multicomponent intervention research, there is a need "to experimentally manipulate and isolate the impact of the various components determining their relative effects” (Vaughn et al., 2011, p. 959).

\section{Future Research}

The results of our study corroborate the view that SBI enhances problem solving involving ratio, proportion, and percent and was found to be more effective than regular mathematics instruction. Based on the study findings, there are several possibilities for future research. First, we intend to investigate the differential benefits of this approach with urban, suburban, and rural students in a randomized controlled trial with random assignment of teachers to treatment. Second, we will continue to explore ways of improving SBI so that it can improve students' problem solving beyond the target domain (e.g., proportion). Third, our conceptualization of procedural flexibility relates to the ability to select the strategy (cross multiplication using ratios, the equivalent fractions strategy, or the unit rate strategy) that would be deemed most efficient in solving the problem based on the numbers in the problems. Unfortunately, we did not assess the strategy choices that students employed in this study to understand whether procedural flexibility had an impact, not only on accuracies, but also on 
strategy choices in the posttest, which would be an important issue to explore in future research. Finally, we are also interested in the sustainability of SBI and think it is worthwhile to examine whether student learning accrues in SBI-experienced teachers' classrooms as compared to SBInovice teachers’ classrooms. 


\section{References}

Ahl, V. A., Moore, C. F., \& Dixon, J. A. (1992). Development of intuitive and numerical proportional reasoning. Cognitive Development, 7, 81-108. doi:10.1016/08852014(92)90006-D

Adjiage, R., \& Pluvinage, F. (2007). An experiment in teaching ratio and proportion. Educational Studies in Mathematics, 65, 149-175. doi: 10.1007/s10649-006-9049-x

Behr, M., Harel, G., Post, T., \& Lesh, R. (1992). Rational number, ratio and proportion. In D. Grouws (Ed.), Handbook of Research on Mathematics Teaching and Learning (pp. 296333). NY: Macmillan Publishing.

Billstein, R. \& Williamson, J. (2008). Math Thematics book 2. Evanston, IL: McDougal Littell.

Cai, J., \& Wang, T. (2006). U.S. and Chinese teachers' conceptions and constructions of representations: A case of teaching ratio concept. International Journal of Science and Mathematics Education, 4, 145-186.

Carpenter, T. P., Fennema, E., Franke, M. L., Levi, L., \& Empson, S. B. (1999). Children’s mathematics: Cognitively guided instruction. Portsmouth, N.H.: Heinemann.

Chen, Z. (1999). Schema induction in children's analogical problem solving. Journal of Educational Psychology, 91(4), 703-715.

Common Core State Standards Initiative. (2010). Common Core State Standards for mathematics. Retrieved from http://www.corestandards.org/assets/CCSSI_Math\%20Standards.pdf.

Day, R., Frey, P., \& Howard, A. C. (2009). Math Connects Course 3. New York, NY: Glencoe/McGraw Hill. 
Edens, K., \& Potter, E. (2006). How students “unpack” the structure of a word problem: Graphic representations and problem solving. School Science and Mathematics, 108, 184-196.

Fuchs, L. S., Powell, S. R., Seethaler, P. M., Cirino, P. T., Fletcher, J. M., Fuchs, D., Hamlett, C. L., \& Zumeta, R. O. (2009). Remediating number combination and word problem deficits among students with mathematics difficulties: A randomized control trial. Journal of Educational Psychology, 101, 561-576. doi:10.1037/a0014701

Fuchs, L. S., Seethaler, P. M., Powell, S. R., Fuchs, D., Hamlett, C. L., \& Fletcher, J. M. (2008). Effects of preventative tutoring on the mathematical problem solving of third-grade students with math and reading difficulties. Exceptional Children, 74(2), 155-173.

Fuchs, L. S., Zumeta, R. O., Schumacher, R. F., Powell, S. R., Seethaler, P. M., Hamlett, C. L., \& Fuchs, D. (2010). The effects of schema-broadening instruction on second graders' word-problem performance and their ability to represent word problems with algebraic equations: A randomized control study. The Elementary School Journal, 110(4), 440-463.

Fujimura, N. (2001). Facilitating children's proportional reasoning: A model of reasoning processes and effects of intervention on strategy change. Journal of Educational Psychology, 93(3), 589-603. doi: 10.1037/0022-0663.93.3.589

Fuson, K.C., \& Abrahamson, D. (2005). Understanding ratio and proportion as an example of the apprehending zone and conceptual-phase problem-solving models. In J. Campbell (Ed.), Handbook of mathematical cognition (pp. 213-234). New York: Psychology Press.

Fuson, K. C., \& Willis, G. B. (1989). Second graders' use of schematic drawings in solving addition and subtraction word problems. Journal of Educational Psychology, 81, 514-520. doi:10.1037/0022-0663.81.4.514 
Goldin, G. (1992). Meta-analysis of problem-solving studies: A critical response. Journal for Research in Mathematical Education, 23, 274-283.

Greer, B. (1992). Multiplication and division as models of situations. In D. Grouws (Ed.), Handbook of research on mathematics teaching and learning (pp. 276-295). New York: Macmillan.

Hatano, G. (2003). Foreword. In A. J. Baroody \& A. Dowker (Eds.), The development of arithmetic concepts and skills (pp. xi-xiii). Mahwah, NJ: Lawrence Erlbaum.

Hedges, L. V. (2007). Effect sizes in cluster-randomized designs. Journal of Educational and Behavioral Statistics, 32, 341-370. doi:10.3102/1076998606298043

Hegarty, M., \& Kozhevnikov, M. (1999). Types of visual-spatial representations and mathematical problem solving. Journal of Educational Psychology, 91(4), 684-689.

Hembree, R. (1992). Experiments and relational studies in problem solving: A meta-analysis. Journal for Research in Mathematical Education, 23, 242-273.

Jitendra, A. K., Griffin, C., Haria, P., Leh, J., Adams, A., \& Kaduvetoor, A. (2007). A comparison of single and multiple strategy instruction on third grade students' mathematical problem solving. Journal of Educational Psychology, 99(1), $115 \mathrm{e} 127$. doi:10.1037/0022-0663.99.1.115.

Jitendra, A. K., Griffin, C., McGoey, K., Gardill, C., Bhat, P., \& Riley, T. (1998). Effects of mathematical word problem solving by students at risk or with mild disabilities. Journal of Educational Research, 91(6), 345e356. doi:10.1080/00220679809597564.

Jitendra, A. K., Star, J., Starosta, K., Leh, J., Sood, S., Caskie, G., et al. (2009). Improving students' learning of ratio and proportion problem solving: the role of schema-based instruction. Contemporary Educational Psychology, 34, $250 \mathrm{e} 264$. 
doi:10.1016/j.cedpsych.2009.06.001.

Jitendra, A.K., Star, J.R., Rodriguez, M., Lindell, M., \& Someki, F. (2011). Improving students' proportional thinking using schema-based instruction. Learning and Instruction, 21, 731745.

Jitendra, A. K., Woodward, J., \& Star, J. R. (2011). Middle school students' thinking about ratios and proportions. In R. Gersten \& R. Newman-Gonchar (Eds.), Understanding RTI in mathematics: Proven Methods and Applications (pp. 127-150). Baltimore, MD: Paul H. Brookes.

Kalyuga, S. (2006). Rapid cognitive assessment of learners’ knowledge structures. Learning and Instruction, 16, 1-11. doi:10.1016/j.learninstruc.2005.12.002

Karplus, R., Pulos, S., \& Stage, E. (1983). Early adolescents’ proportional reasoning on 'rate’ problems. Educational Studies in Mathematics, 14, 219-233.

Koichu, B., Berman, A., \& Moore, M. (2007). The effect of promoting heuristic literacy on the mathematical aptitude of middle-school students. International Journal of Mathematical Education in Science and Technology, 38(1), 1-17. doi:10.1080/00207390600861161

Lajoie, S. P. (2003). Transitions and trajectories for studies of expertise. Educational Researcher, 32 (8), 21-25.

Lamon, S. (1999). Teaching fractions and ratios for understanding: Essential content knowledge and instructional strategies for teachers. Mahwah, NJ: Lawrence Erlbaum.

Lamon, S. J. (2007). Rational numbers and proportional reasoning: Toward a theoretical framework for research. In F. K. Lester, Jr. (Ed.), Second handbook of research on mathematics teaching and learning (pp. 629-668). National Council of Teachers of Mathematics, Charlotte, NC: Information Age Publishing. 
Larson, R., Boswell, L., Kanold, T.D., \& Stiff, L. (2007). Math Course 2. Evanston, IL: McDougal Littell.

Lesh, R., Post, T., \& Behr, M. (1988). Proportional Reasoning. In J. Hiebert \& M. Behr (Eds.) Number Concepts and Operations in the Middle Grades (pp. 93-118). Reston, VA: Lawrence Erlbaum \& National Council of Teachers of Mathematics.

Lesh, R., \& Zawojewski, J. (2007). Problem solving and modeling. In F. K. Lester, Jr. (Ed.), Second handbook of research on mathematics teaching and learning (pp. 763-804). National Council of Teachers of Mathematics, Charlotte, NC: Information Age Publishing. Litwiller, B., \& Bright, G. (2002). Making sense of fractions, ratios, and proportions. Reston, VA: National Council of Teachers of Mathematics.

Lo, J., \& Watanabe, T. (1997). Developing ratio and proportion schemes: A story of a fifth grader. Journal for Research in Mathematics Education, 28, 216-236.

Lobato, J., Ellis, A. B., Charles, R. I., \& Zbiek, R. M. (2010). Developing essential understanding of ratios, proportions \& proportional reasoning. Reston, VA: National Council of Teachers of Mathematics.

Marshall, S. P. (1995). Schemas in problem solving. New York: Cambridge University Press.

Mayer, R.E. (1999). The promise of educational psychology Vol. I: Learning in the content areas. Upper Saddle River, NJ: Merrill Prentice Hall.

National Center for Education Statistics. (2009). National assessment of educational progress: U.S. Department of Education Institute of Education Sciences.

National Mathematics Advisory Panel (2008). Foundations for Success: The Final Report of the National Mathematics Advisory Panel. Washington, DC: U.S. Department of Education. 
Pape, S. J., \& Tchoshanov, M. A. (2001). The role of representation(s) in developing mathematical understanding. Theory into Practice, 40, 118-127.

Pólya, G. (1990). How to solve it. London: Penguin. (Originally published in 1945)

Quilici, J. L., \& Mayer, R. E. (1996). Role of examples in how students learn to categorize statistics word problems. Journal of Educational Psychology, 88, 144-161.

Quilici, J. L., \& Mayer, R. E. (2002). Teaching students to recognize structural similarities between statistics word problems. Applied Cognitive Psychology, 16, 325-342.

Raudenbush, S. W., \& Bryk, A. S. (2002). Hierarchical linear models: Applications and data analysis methods (2nd ed.). Thousand Oaks, CA: Sage Publications.

Raudenbush, S.W., Bryk, A.S, \& Congdon, R. (2004). HLM 6 for Windows (Version 6.04) [Computer software]. Lincolnwood, IL: Scientific Software International.

Rittle-Johnson, B, \& Star, J.R. (2007). Does comparing solution methods facilitate conceptual and procedural knowledge? An experimental study on learning to solve equations. Journal of Educational Psychology, 99(3), 561-574.

Schoenfeld, A. H. (1992). Learning to think mathematically: Problem solving, metacognition, and sense making in mathematics. In D. Grouws (Ed.), Handbook of research on mathematics teaching and learning (pp. 334-370). New York:McMillan.

Sellke, D. H., Behr, M. J., \& Voelker, A. M. (1991). Using data tables to represent and solve multiplicative story problems. Journal for Research in Mathematics Education, 22(1), pp. 30-38.

Silver, E. A., Ghousseini, H., Gosen, D., Charalambous, C., \& Strawhun, B. (2005). Moving from rhetoric to praxis: Issues faced by teachers in having students consider multiple 
solutions for problems in the mathematics classroom. Journal of Mathematical Behavior, 24, 287-301.

Star, J.R. (2005). Reconceptualizing procedural knowledge. Journal for Research in Mathematics Education, 36(5), 404-411.

Star, J.R. (2007). Foregrounding procedural knowledge. Journal for Research in Mathematics Education, 38(2), 132-135.

Stylianou, D. A. (2011). An examination of middle school students' representation practices in mathematical problem solving through the lens of expert work: Towards an organizing scheme. Educational Studies in Mathematics, 76, 265-280. doi: 10.1007/s10649-010-9273-2

Sweller, J., Chandler, P., Tierney, P., Cooper, M. (1990). Cognitive load as a factor in the structuring of technical material. Journal of Experimental Psychology: General, 119(2), 176-192.

Tourniaire, F., \& Pulos, S. (1985). Proportional reasoning: A review of the literature. Educational Studies in Mathematics, 16(2), 181-204.

Van Dooren, W. V., De Bock, D. D. \& Verschaffel, L. (2010). From addition to multiplication ... and back: The development of students' additive and multiplicative reasoning skills. Cognition and Instruction, 28, 360-381.

Vaughn, S., Klingner, J. K., Swanson, E. A., Boardman, A. G., Roberts, G., Mohammed, S. S., \& Stillman-Spisak, S. J. (2011). Efficacy of collaborative strategic reading with middle school students. American Educational Research Journal, 48, 938-964. doi: 10.3102/0002831211410305

Vergnaud, G. (1983). Multiplicative structures. In R. Lesh \& M. Landau (Eds.), Acquisition of mathematics concepts and processes (pp. 127-174). Orlando, FL: Academic Press. 
Xin, Y. P. (2008). The effect of schema-based instruction in solving word problems: An emphasis on pre-algebraic conceptualization of multiplicative relations. Journal for Research in Mathematics Education. 39, 526-551.

Xin, Y. P., Jitendra, A. K., \& Deatline-Buchman, A. (2005). Effects of mathematical word problem solving instruction on students with learning problems. Journal of Special Education, 39(3), 181-192.

Yekovich, F. R., Thompson, M. A., \& Walker. C. H. (1991). Generation and verification of inferences by experts and trained nonexperts. American Educational Research Journal, 28, 189-209.

Yoon, K. S., Duncan, T., Lee, S. W.-Y., Scarloss, B., \& Shapley, K. (2007). Reviewing the evidence on how teacher professional development affects student achievement (Issues \& Answers Report, REL 2007-No. 033). Washington, DC: U.S. Department of Education, Institute of Education Sciences, National Center for Education Evaluation and Regional Assistance, Regional Educational Laboratory Southwest. Retrieved from http://ies.ed.gov/ncee/edlabs 
Table 1.

Student Demographic Information by Condition

\begin{tabular}{|c|c|c|c|c|c|c|c|c|c|c|c|c|}
\hline \multirow[b]{2}{*}{ Variable } & \multicolumn{4}{|c|}{ Schema-based Instruction } & \multicolumn{4}{|c|}{ Control } & \multicolumn{4}{|c|}{ Total } \\
\hline & $M$ & $S D$ & $n$ & $(\%)$ & $M$ & $S D$ & $n$ & $(\%)$ & $M$ & $S D$ & $N$ & $(\%)$ \\
\hline Age (in years) & 12.81 & 0.40 & 571 & 51.26 & 12.85 & 0.36 & 543 & 48.74 & 12.83 & 0.38 & 1114 & \\
\hline \multicolumn{13}{|l|}{ Gender } \\
\hline Male & & & 288 & 50.30 & & & 264 & 48.60 & & & 552 & 49.50 \\
\hline Female & & & 285 & 49.70 & & & 279 & 51.40 & & & 564 & 50.50 \\
\hline \multicolumn{13}{|l|}{ Ethnicity } \\
\hline American Indian & & & 9 & 1.60 & & & 7 & 1.30 & & & 16 & 1.40 \\
\hline Asian & & & 68 & 11.90 & & & 57 & 10.50 & & & 125 & 11.20 \\
\hline Hispanic & & & 57 & 10.00 & & & 49 & 9.00 & & & 106 & 9.50 \\
\hline Black & & & 92 & 16.10 & & & 99 & 18.20 & & & 191 & 17.10 \\
\hline Caucasian & & & 345 & 60.40 & & & 331 & 58.20 & & & 676 & 60.70 \\
\hline Free/Reduced Lunch & & & 188 & 33.00 & & & 193 & 35.50 & & & 382 & 34.20 \\
\hline Special Education & & & 73 & 12.70 & & & 43 & 7.90 & & & 116 & 10.50 \\
\hline ELL & & & 42 & 7.30 & & & 36 & 6.60 & & & 78 & 7.00 \\
\hline
\end{tabular}

Note: $M=$ mean; $S D$ = standard deviation; $n$ = sample size; ELL= English language learner. Sample sizes on the demographic variables differ because of missing data; descriptive statistics are presented for all students who provided information on each variable. 
Table 2.

Examples of Problem Types

Example of Problem

Last weekend, Will helped his father clean the

garage. For every 3 hours of work, he took a 2 hour break. If he worked for 6 hours (not including breaks), how many hours did he spend taking breaks?

On a geography map test that was worth 25 points, Janie got a grade of $20 \%$. How many points did she earn on the geography test?

Mariah and Alex both started exercising more and each lost 8 pounds. Before they started exercising, Mariah weighed 160 lbs. and Alex weighed 200 lbs. Who had the greater percent of decrease in weight, Mariah or Alex?
Problem Type

\section{Ratio}

Compared

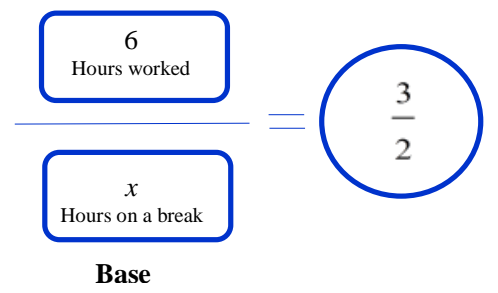

Percent: Part-whole comparison

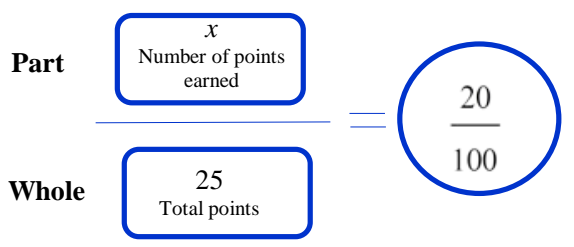

Percent of change

Mariah:

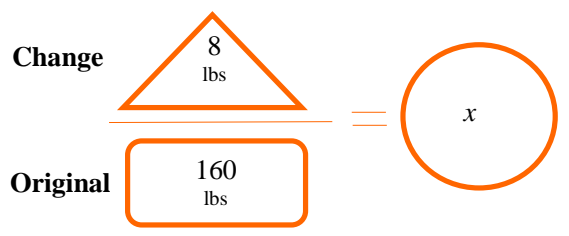

Alex:

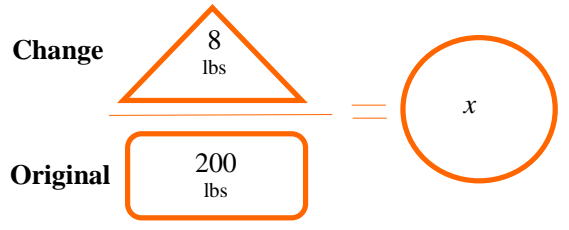


Carlos is on the school's track team. He takes 54 minutes to run 6 miles. How long did it take him to run 2 miles?

Tammy looks on a map and finds that Atlantic City beach is $7 \mathrm{~cm}$ from the hotel where she is staying. The scale of the map is $4 \mathrm{~cm}=6$ miles. How many miles away is the beach from the hotel?

Ricardo took his family out to dinner. The bill was \$60. If Ricardo wants to leave the server a $15 \%$ tip, how much money should he leave? What was the total cost of the meal?

\section{Proportion}

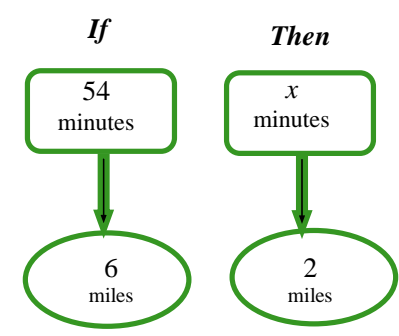

Scale Drawing

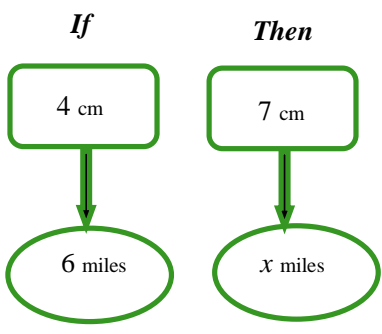

Percent of change:

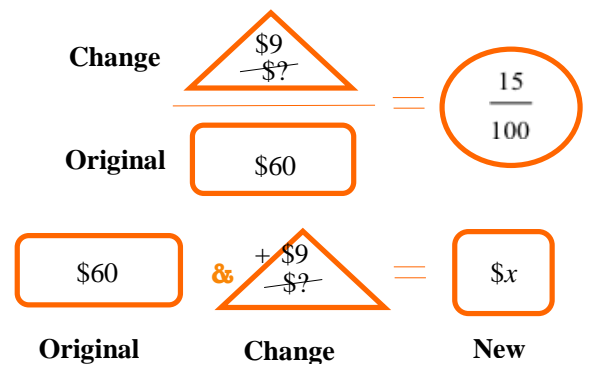

Keisha’s parents lend Keisha \$200 so she can buy an iPod Nano. They charge Keisha 3\% simple annual interest. What will be the total amount that Keisha will owe her parents in 1 year?
Simple interest

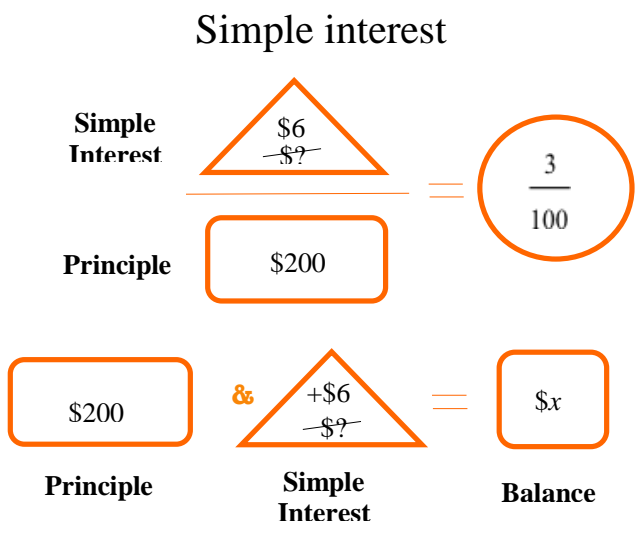


Table 3.

Summary of Fidelity Observations in SBI and Control Classrooms

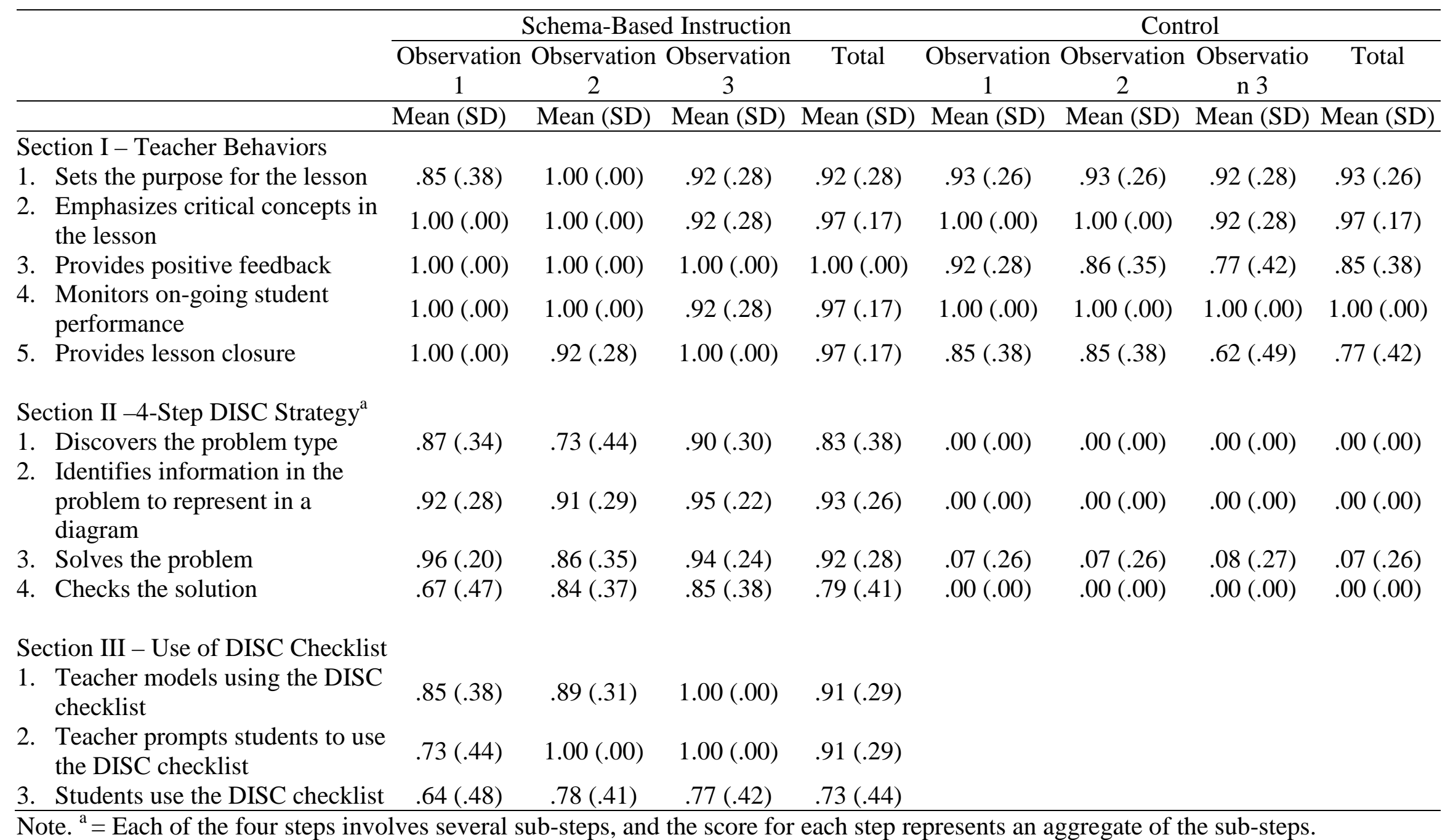


Table 4.

Descriptive Statistics for Problem Solving Measures by Condition and School

\begin{tabular}{|c|c|c|c|c|c|c|c|c|c|c|c|c|c|c|}
\hline & \multicolumn{7}{|c|}{ Control } & \multicolumn{7}{|c|}{ Schema-based Instruction } \\
\hline & \multicolumn{2}{|c|}{ Pretest } & \multicolumn{2}{|c|}{ Posttest } & \multicolumn{2}{|c|}{$\begin{array}{l}\text { Delayed } \\
\text { Posttest }\end{array}$} & \multirow[b]{2}{*}{$n$} & \multicolumn{2}{|c|}{ Pretest } & \multicolumn{2}{|c|}{ Posttest } & \multicolumn{2}{|c|}{$\begin{array}{l}\text { Delayed } \\
\text { Posttest }\end{array}$} & \multirow[b]{2}{*}{$n$} \\
\hline & $M$ & $S D$ & $M$ & $S D$ & $M$ & $S D$ & & $M$ & $S D$ & $M$ & $S D$ & $M$ & $S D$ & \\
\hline School A & 11.49 & 4.13 & 14.94 & 4.65 & 15.04 & 4.63 & 88 & 11.04 & 4.16 & 17.31 & 5.57 & 16.19 & 5.24 & 93 \\
\hline School B & 14.43 & 4.66 & 17.74 & 5.45 & 17.69 & 5.60 & 134 & 13.68 & 4.84 & 17.96 & 6.00 & 17.47 & 5.26 & 140 \\
\hline School C & 11.12 & 4.30 & 14.67 & 5.43 & 12.70 & 5.02 & 77 & 11.01 & 4.36 & 15.21 & 5.20 & 14.67 & 5.72 & 76 \\
\hline School D & 12.60 & 5.45 & 17.28 & 5.26 & 16.44 & 4.91 & 36 & 14.58 & 4.85 & 20.29 & 4.19 & 18.98 & 4.05 & 59 \\
\hline School E & 13.83 & 4.22 & 16.74 & 5.10 & 17.15 & 5.09 & 122 & 13.57 & 5.20 & 17.40 & 5.91 & 17.22 & 5.82 & 141 \\
\hline School F & 15.93 & 5.24 & 20.27 & 5.46 & 19.97 & 5.02 & 112 & 16.01 & 4.96 & 21.87 & 4.96 & 21.17 & 4.49 & 85 \\
\hline Total & 13.59 & 4.90 & 17.16 & 5.56 & 16.89 & 5.55 & 569 & 13.35 & 5.05 & 18.18 & 5.82 & 17.57 & 5.54 & 594 \\
\hline
\end{tabular}

Note. $M=$ mean; $\mathrm{SD}=$ standard deviation, $n=$ sample size. 
Table 5.

Descriptive Statistics for Transfer Measures by Condition and School

\begin{tabular}{lcccccccccc}
\hline & \multicolumn{4}{c}{ Control } & \multicolumn{4}{c}{ Schema-based Instruction } \\
\cline { 2 - 11 } & \multicolumn{2}{c}{ Pretest } & \multicolumn{1}{c}{ Posttest } & \multicolumn{3}{c}{ Pretest } & \multicolumn{3}{c}{ Posttest } \\
\cline { 2 - 11 } & $M$ & $S D$ & $M$ & $S D$ & $n$ & $M$ & $S D$ & $M$ & $S D$ & $n$ \\
\hline School A & 9.19 & 3.03 & 10.52 & 3.30 & 88 & 8.97 & 3.15 & 10.37 & 3.75 & 93 \\
School B & 11.34 & 3.20 & 12.00 & 3.33 & 134 & 10.52 & 3.20 & 11.59 & 3.14 & 140 \\
School C & 8.53 & 3.36 & 9.58 & 3.44 & 77 & 9.19 & 3.21 & 10.64 & 3.30 & 76 \\
School D & 9.71 & 3.33 & 11.80 & 2.89 & 36 & 11.25 & 2.76 & 12.29 & 2.65 & 59 \\
School E & 10.43 & 3.04 & 11.55 & 3.04 & 122 & 10.43 & 2.88 & 11.52 & 3.36 & 141 \\
School F & 11.81 & 3.04 & 12.85 & 3.27 & 112 & 12.10 & 2.95 & 13.67 & 2.39 & 85 \\
\hline Total & 10.43 & 3.33 & 11.50 & 3.39 & 569 & 10.39 & 3.19 & 11.64 & 3.32 & 594 \\
\hline
\end{tabular}

Note. $M=$ mean; $S D=$ standard deviation, $n=$ sample size. 
Table 6.

HLM Full Model for Problem Solving Posttest

\begin{tabular}{|c|c|c|c|c|c|}
\hline Fixed Effect & Coefficient & $S E$ & $t$ & $d f$ & $P$ \\
\hline Intercept, G00 & 17.547 & 0.173 & 101.60 & 31 & 0.000 \\
\hline Condition, G01 & 1.478 & 0.370 & 3.99 & 31 & 0.000 \\
\hline Caucasian, G02 & -3.334 & 2.129 & -1.57 & 31 & 0.127 \\
\hline Free/reduced lunch, G03 & -2.376 & 2.538 & -0.94 & 31 & 0.357 \\
\hline Special ed. status, G04 & -5.549 & 2.378 & -2.33 & 31 & 0.026 \\
\hline Pretest, G05 & 0.925 & 0.153 & 6.03 & 31 & 0.000 \\
\hline School A, G06 & -0.361 & 1.556 & -0.23 & 31 & 0.818 \\
\hline School B, G07 & -0.973 & 0.669 & -1.45 & 31 & 0.156 \\
\hline School C, G08 & -1.870 & 1.700 & -1.10 & 31 & 0.280 \\
\hline School D, G09 & -0.134 & 0.858 & -0.16 & 31 & 0.877 \\
\hline School E, G010 & -1.271 & 0.612 & -2.08 & 31 & 0.046 \\
\hline Ethnicity slope, G10 & 0.460 & 0.315 & 1.46 & 1070 & 0.145 \\
\hline Free/reduced lunch slope, G20 & -0.648 & 0.334 & -1.94 & 1070 & 0.052 \\
\hline Special ed. status slope, G30 & -1.205 & 0.438 & -2.75 & 1070 & 0.006 \\
\hline Pretest slope, G40 & 0.661 & 0.028 & 23.64 & 1070 & 0.000 \\
\hline Random Effect & $S D$ & Variance & $\chi^{2}$ & $d f$ & $P$ \\
\hline Intercept, U0 & 0.78 & 0.61 & 61.08 & 31 & 0.001 \\
\hline Residual, R & 4.01 & 16.05 & & & \\
\hline
\end{tabular}


Table 7.

HLM Full Model for Problem Solving Delayed Posttest

\begin{tabular}{|c|c|c|c|c|c|}
\hline Fixed Effect & Coefficient & $S E$ & $t$ & $d f$ & $P$ \\
\hline Intercept, G00 & 17.001 & 0.141 & 120.70 & 31 & 0.000 \\
\hline Condition, G01 & 1.169 & 0.302 & 3.88 & 31 & 0.001 \\
\hline Caucasian, G02 & -1.097 & 1.724 & -0.64 & 31 & 0.529 \\
\hline Free/reduced lunch, G03 & -2.273 & 2.082 & -1.09 & 31 & 0.284 \\
\hline Special ed. status, G04 & -5.018 & 1.941 & -2.59 & 31 & 0.015 \\
\hline Pretest, G05 & 0.831 & 0.126 & 6.62 & 31 & 0.000 \\
\hline School A, G06 & 0.033 & 1.269 & 0.03 & 31 & 0.979 \\
\hline School B, G07 & -0.898 & 0.540 & -1.66 & 31 & 0.106 \\
\hline School C, G08 & -2.023 & 1.385 & -1.46 & 31 & 0.154 \\
\hline School D, G09 & -0.815 & 0.692 & -1.18 & 31 & 0.248 \\
\hline School E, G010 & -1.007 & 0.497 & -2.03 & 31 & 0.051 \\
\hline Ethnicity slope, G10 & 0.395 & 0.313 & 1.26 & 1070 & 0.208 \\
\hline Free/reduced lunch slope, G20 & -0.749 & 0.331 & -2.26 & 1070 & 0.024 \\
\hline Special ed. status slope, G30 & -0.415 & 0.435 & -0.96 & 1070 & 0.340 \\
\hline Pretest slope, G40 & 0.632 & 0.028 & 22.76 & 1070 & 0.000 \\
\hline Random Effect & $S D$ & Variance & $\chi^{2}$ & $d f$ & $P$ \\
\hline Intercept, U0 & 0.45 & 0.20 & 41.37 & 31 & 0.101 \\
\hline Residual, R & 3.98 & 15.82 & & & \\
\hline
\end{tabular}

